\title{
13
}

\section{The Evolution of a Teacher-}

Professor: Applying Behavior Change Theory to Faculty Development

\section{Fred Hebert and Marty Loy}

University of Wisconsin-Stevens Point

This chapter introduces the sage, the thinker, the builder, and the master as four evolutionary archetypes to use as identifiable characters in the process of teaching development. Once defined, behavior change theory is applied, and stagespecific strategies are used to aid these archetypes in their evolutionary process.

\section{INTRODUCTION}

T has been said that teachers undergo a metamorphosis of sorts, and Ithat over time, they evolve through a process of change, from novice, inexperienced teachers into expert/master teachers (Bain, 1998; Perry, 1992). Many studies have confirmed this process, defining the typical learning curve for faculty, pinpointing critical events in that development, and suggesting strategies (usually in the form of faculty development programs) to enhance or even initiate such development (Bain,1998; Perry, 1992; Shulman, 1993). As a result, most universities are creating teaching-learning centers, initiating teaching enhancement activities, and sending faculty to teaching conferences to facilitate the learning of new teaching pedagogy and improvement of teaching methods (Hargreaves \& Dawe, 1989). There is no question that these faculty 
development programs work (Angelo, 1991; Cerbin, 1992; Hutchings, 1996). The question is: Can they work better?

One answer to this question may lie in the work of health psychologist James Prochaska. Prochaska, DiClemente, and Norcross (1992) developed a stage-of-change theory which has helped to clarify how shifts in behavior occur, enabling the design of stage-specific strategies to move people more efficiently through the change process. When applied to the evolutionary process master teachers go through, this staging theory can help determine when to employ effective strategies to facilitate teacher growth.

This chapter will introduce the sage, the thinker, the builder, and the master as four evolutionary archetypes to use as identifiable characters in the process of teaching development. Once a teacher's archetype is identified, he or she will be aided in the process of change through Prochaska's six stages. The best strategies for growth on the evolutionary continuum are determined and offered to the teacher.

\section{Behavior Change Theory}

Prochaska's behavior change theory includes six stages ordered along a continuum of motivational readiness to change. Pre-contemplation is considered the first stage of change in this continuum, as it precludes all other stages. Contemplation, preparation, action, maintenance, and finally, termination, follow.

\section{The Pre-Contemplation Stage}

Teachers in the pre-contemplation stage have no intention of changing their teaching behavior. They often feel change is hopeless, and use denial and defensiveness to justify their classroom behavior. Pre-contemplative teachers might justify their lack of development by insisting that a teacher's role is to deliver content and not entertain students. Poor teacher evaluations are often discounted because of the rigor of their class or their lack of popularity. Teachers in this stage feel safe teaching in a way they are familiar and comfortable with.

\section{The Contemplation Stage}

Teachers in the contemplation stage begin to think seriously about changing, recognizing they can improve their approach to teaching. Change could be subtle (merely refining current practices) or dramatic (considering a move from a teacher-centered to student-centered ap- 
proach). Contemplating teachers begin to critically reflect on their teaching. However, because they are often uncertain of their ability to change, and because they may not know where to begin, they may view change as threatening to their professional security and comfort. Teachers in this stage may be waiting for the right moment, or even believe change will simply occur with the passing of time.

\section{The Preparation Stage}

In the preparation stage, teachers begin to establish a plan for action, focus on the future more than the past, and are excited about perceived growth in their teaching. Preparing for change might be illustrated through continued contemplation, syllabus reconstruction, creating a file of new teaching ideas, reconstructing classroom activities, and talking with colleagues about anticipated changes. Once teachers enter the preparation stage, they typically feel good about plans and are energized by the growth possibilities associated with change.

\section{The Action Stage}

Action is the overt modification of teaching practice, considered the busiest and most difficult stage of change. Action is most visible to others, and because of the private nature of teaching, the most frightening. Confidence and motivation toward lofty goals are necessary in this stage, since action is challenging and difficult. Furthermore, initial attempts at new teaching methods may fail, making familiar methods easy to fall back upon. Teachers' motives for change, therefore, must be clarified and reaffirmed. Reaffirmation is often expressed in statements such as, "I want to support student learning" or "my goal is to improve students' appreciation for learning."

\section{The Maintenance Stage}

The maintenance stage involves making the change a permanent part of teaching, and therefore presents many additional challenges to faculty implementing classroom changes. The illusion of easy change, or failure to acknowledge the long, ongoing process of change, can prevent these transformations from becoming permanent. Repeated failures, in addition, may force a teacher back into old behaviors. Three common challenges to moving beyond the action stage into maintenance are overconfidence, suggested in statements such as, "this is easy" or "this will make all the difference"; temptation to fall back into old patterns, reflected in statements such as, "it was easier back when I just lectured" and "I had 
more control before I began discussions"; and self-blame, characterized by self-deflating remarks such as, "teaching in this way simply does not work for me" or even worse, "I don't have what it takes to be that kind (learner-centered) of teacher."

\section{The Termination Stage}

Termination is a stage often considered fictitious, as it indicates no further need to change and grow. There are no setbacks, only successes. Teachers in this stage are in all likelihood back in pre-contemplation.

\section{The Four Evolutionary Archetypes: The Sage, the Thinker, the Builder, and the Master}

The sage, the thinker, the builder, and the master are four evolutionary archetypes developed through our research, conversations, and experiences. The attributes of these characters help define the process of teacher development. Once these characters are defined, we apply strategies from Prochaska's six stages of change to suggest best strategies for facilitating growth on the evolutionary continuum.

While we believe there are teachers who are improving progress through these stages, we do not believe all teachers move through all stages. In fact, a large number of teaching professors are unable to evolve beyond the first stage, the sage. There may be many reasons for this, including fear of change, comfort, perceived success as a lecturer, lack of support for change, and not knowing other ways of teaching. After all, the lecture-dominated method of college teaching has been preferred for centuries and change will occur slowly, if at all. Movement through these stages is a dynamic process, often spiraling up and down on the evolutionary continuum. Teachers may find themselves straddling two stages or moving between stages at any given time during their evolutionary journey.

\section{The Sage}

The sage walks into the class, proceeds to the front of the room, finds a comfortable position, and begins to disseminate information. This teacher employs the long-dominant lecture mode and is truly the "sage on the stage." This mode of teaching is easy and nonthreatening. Generally accomplished as lecturers, sages may be capable of gaining and maintaining the attention of their audience. Regardless of one's skill, reflection is based on the teacher's efforts, not on the learning experience of 
the students. The sage may employ an occasional visual, overhead, or PowerPoint presentation, but the discourse remains teacher-centered. Professors who are sages know more about their subject matter than any student, and only provide students with the information required to gain credit in the course. Sages tend to enjoy the power and importance they gain through this approach. Meanwhile, students are passive recipients, taking dutiful notes, sleeping, or skipping class because they know the lectures mirror the textbook. Education is "being done" to these students, rather than provided to them, with a sense of ownership in the educational process. In this heavily teacher-centered approach, the learner is not given much consideration.

This is not to suggest lectures are ineffective or educationally unsound. In fact, in the evolutionary process, lectures serve a definite purpose. When most people begin teaching in higher education, they have a great deal of knowledge requiring organization in order for others to benefit. Quite often, the process of preparing lectures helps organize thoughts, builds confidence, and actually facilitates teacher growth. Most PhD programs do not train their graduates to be teachers; therefore, new teachers will primarily teach as they were taught, via lecture. Most teachers in higher education want to teach well and try hard to be the best teachers possible. Those who begin their teaching careers as sages are in Prochaska's pre-contemplation stage, and will benefit most from consciousness-raising activities.

Consciousness-raising activities allow pre-contemplators to see themselves as others do. Typical strategies involve formative classroom observations by a trusted mentor who provides honest feedback, suggests alternative teaching possibilities, and engages in conversations about innovative approaches to teaching. Sages need opportunities to view good teaching in nonthreatening environments in order to generate the necessary interest to motivate them into moving into the next stage. Additionally, attendance at teaching-learning conferences may provide a forum for further consideration of personal growth.

\section{The Thinker}

The thinker experiences enough cognitive dissonance with the dominant lecture mode to begin to consider different approaches to teaching. This is not to intimate that faculty members employing the lecture mode of teaching are nonthinkers; rather, it implies they are failing to think of the learning experience from the students' point of view. Thinkers have received information or feedback causing them to reflect on methods of 
teaching in their classrooms. They have begun to consider the impact of their efforts on student learning.

A teacher-thinker begins to question the merits of lecture, becomes aware of the issues related to student learning, and realizes the classroom can become more student-centered. Thoughts of moving toward a student-centered approach are intimidating, as lecturing is comfortable, enjoyable, and a means of disseminating large amounts of content in a short period of time. Especially if they are good at delivering lectures, thinkers may wonder, "Why change a comfortable, longstanding, timetested way of disseminating information?" Thinkers may ask this question over and over, eventually moving forward, or remaining in the thinker stage.

At first, the thinker must move through the contemplation stage, reflecting on old teaching strategies and considering new approaches. Because contemplating teachers are curious about what change might mean to their teaching, strategies for working with those in the contemplation stage include continued consciousness-raising activities. As stated earlier, thinkers may not be completely convinced their approach to teaching is in need of change or that they possess the ability to change. Vigorous consciousness-raising, such as involvement in discussions highlighting pitfalls of poor teaching in nonthreatening ways, or encouraging collaboration with master teachers, invite contemplators to act on their curiosity and to commit to change. Reassurance and support are essential ingredients to moving contemplators into preparing for action.

After considering all options, thinkers move into Prochaska's third stage of change: preparation. Strategies for working with thinkers at this stage include encouraging critical reflection and committing ideas to a plan. Preparing for change, creating detailed plans, making intentions public, and seeking encouragement from master teachers are helpful approaches in preparing to take action. It is important to provide continued encouragement and support. Supportive strategies include encouraging attendance at teaching-learning workshops, providing appropriate books, making information available on successful teaching strategies, and establishing freedom from summative evaluation for the purpose of tenure. In this stage, it is important to shape expectations, as it is often detrimental to undertake large, wholesale changes in teaching philosophy or classroom behavior. Suggesting smaller, incremental, and manageable changes might be far more productive to someone contemplating action. Mentoring thinkers requires a "cheerleading" approach, involving a commitment of time, encouragement, and support. 


\section{The Builder}

When thinkers decide to undertake new approaches, they typically move toward the creation of student-centered classrooms. This step moves them out of the thinker stage and places them in the builder stage. Builders leave the personal comfort of the sage and the constant discomfort of the thinker, and move into the domain of the third archetypical character, which could best be described as "controlled chaos." Builders accept that their approach to teaching will become more student-centered, which may lead to less personal control. Teachers who are builders find moving from passive learning to active learning both frightening and exciting. It is frightening to give up classroom control, engaging in spontaneous classroom interactions that could challenge the teacher's position as an expert. Because the teacher becomes a guide as well as a learner, it also becomes exciting to create a student-centered classroom (McKeachie, 1999).

Parker Palmer (1997) refers to a person engaged in student-centered teaching as becoming aware of one's inwardness. For better or worse, students are allowed to witness the conditions of builders' souls as well as gain subject knowledge. Teaching in this way embraces Palmer's belief that we teach who we are and that teaching is essentially a mirror to one's soul. Builders may have similar traits and qualities, and in many cases, may be very different from each other. Some may still employ a great deal of lecture, while others speak very little; some may stay close to their material, and others let loose their imaginations. Some teach with a sense of motivation, while others use intimidation. The common thread connecting them with other builders is their consideration of student learning in their teaching. In other words, they have embraced both subject matter and students. Connecting the two requires courage and openness on the part of the teacher and students. Banner and Cannon (1997) believe these qualities are found in everyone, inherent in all of us. One need not study these qualities so much as become aware of and employ them. They can and must be summoned from within both students and teacher in order for the builder to become the best teacher possible.

The concept of the builder as one who creates experiential opportunities and guided classroom interactions is hardly new to the world of education. John Dewey (1902) recognized the value of interaction and placed the student in the center of the learning experience. Paulo Freire (1971), a noted educational reformer known for giving recognition to prior knowledge and experience to all learners, supported the idea that everyone is capable of learning and capable of contributing to the learning experience of 
others. Active or interactive learning involves "sense-making" and social interaction, leading to generative knowledge that is usable because it is the consequence of complex thinking.

An effective and appropriate technique for one teacher may be completely ineffective and awkward in the hands of another; therefore, teaching in this fashion cannot be reduced to technique. Generally, builders choose from a wide variety of student-centered strategies, including cooperative learning, collaborative learning, problem-based learning, employment of case studies, experiential learning, and/or integrating interactive technology. Students and teachers involve themselves in analysis, evaluation, synthesis, integration, perspective taking, internal dialogue, debate, connection making, and question posing. The variety of perspectives and opinions found within a classroom of individuals (all respected for what they bring to the learning environment) encourages the intellectual discourse necessary for each to grow.

Two stages of change accompany builder growth: action and maintenance. As builders take action, implementing strategies to create studentcentered classrooms, they are faced with many challenges, such as failure, student resistance to change, and lack of support from colleagues. Strategies for facilitating builders in the action stage are directed toward providing further resources, encouragement, and support. Builders who are in the process of implementing new teaching strategies should be afforded opportunities to share successes and failures, while building supportive relationships which provide consistent motivation.

In the action stage, this can be accomplished in a number of ways. Pairing people in mentoring relationships or creating cadres of experienced teachers who understand the multiple challenges involved in maintaining change can encourage a builder to overcome classroom failures. Public recognition, a letter of commendation, or a simple acknowledgement of effort may provide reward and encouragement. Reinforcement is the main goal of mentoring a colleague in the action stage. Builders committed to action require mentors who understand the pitfalls involved in trying something new. Mentors must be equally committed to the principles motivating the builder in the action stage, as well as empathetic listeners with frequent contact to provide encouragement.

Once a change effort becomes permanent, the builder enters the maintenance stage. Faculty development in maintenance requires similar strategies to those found in the action stage; however, the maintenance stage presents additional challenges of overconfidence, temptation to return to old patterns, or lack of confidence. Builders in the maintenance 
stage are often forgotten because of the misconception that they are "over the hump." In fact, maintaining change demands continued attention. Builders who are making their change efforts permanent need peer and administrative support in the form of continued encouragement, frequent reminders, and greater challenges. At this stage, ongoing, less frequent peer support, such as teaching circles, provide collaborative opportunities and venues to consider other new areas of change. Encouraging work on the scholarship of teaching is another viable strategy to help faculty gain comfort with classroom change.

\section{The Master}

To reach the master level is a goal for anyone progressing through the evolutionary process; but, like many goals, is difficult to attain. Striving for mastery is potentially frightening and exciting. Whether builders are trying new techniques or employing tried and true methods, they will have days where everything clicks, and other days where nothing goes as planned. On the days where everything clicks, there is an almost magical feeling present in students and teachers, which remains for a lifetime; these are moments of true mastery. However, for every magical day there are many days that, for a variety of reasons, may not go as well. Teachers may not be as organized as they should be, may be preoccupied, or perhaps not comfortable with the strategy or technique being utilized. Students may be unprepared, disengaged, disinterested, preoccupied, or simply absent. In teaching, hitting one's stride and experiencing mastery in the learning exchange takes time.

It is our belief that the master archetype is attainable, but not sustainable. In fact, teachers who believe they are masters are in all likelihood delusional, retired, or both. This notion fits with termination, the final behavior change stage, a stage Prochaska believes may be nonexistent. If you think you have arrived at this stage, it is a sure indication you have not proceeded back to step one; you are still in pre-contemplation.

\section{Conclusion}

Thinking about teaching is as much an evolutionary process as teaching itself. This framework is grounded in research and faculty development practice, but more so in the professional growth experiences of the authors.

This chapter represents an initial effort to understand how faculty development and behavior change theory are related and suggests the importance of providing well-placed strategies to help teaching professors 
evolve. The four archetypes combined with stages of change provide a framework of markers to identify faculty in the evolutionary process. Once identified, strategies can be targeted to benefit faculty at different points in their evolution. Finally, this framework makes a case for the assessment of faculty growth and change from an incremental, rather than an all or nothing perspective.

\section{REFERENCES}

Angelo, T. A. (1991). Ten easy pieces: Assessing higher learning in four dimensions. New Directions for Teaching and Learning, No. 46. San Francisco, CA: Jossey-Bass.

Bain, K. (1998). What do the best teachers do? Evanston, IL: Northwestern University, Searle Center for Teaching Excellence.

Banner, J. M., \& Cannon, H. C. (1997). The personal qualities of teaching: What teachers do cannot be distinguished from who they are. Change, 29, 40-43.

Cerbin, W. (1992). How to improve teaching with learner centered evaluation. National Teaching and Learning Forum, 1 (6), 6-8.

Dewey, J. (1902). The child and the curriculum: The school and society. Chicago, IL: University of Chicago Press.

Freire, P. (1971). Pedagogy of the oppressed. New York, NY: Herder \& Herder.

Hargreaves, A., \& Dawe, R. (1989). Paths of professional development: Contrived collegiality, collaborative culture, and the case of peer coaching. Teaching and Teacher Education, 6 (3), 227-241.

Hutchings, P. (1996). The peer review of teaching: Progress, issues and prospects. Innovative Higher Education, 20 (4), 221-234.

McKeachie, W. (1999). Teaching tips: A guidebook for the beginning college teacher (10th ed.). Boston, MA: Houghton Mifflin.

Palmer, P. J. (1997). The heart of a teacher: Identity and integrity in teaching. Change, 29, 15-21.

Perry, R. P. (1992). Teaching in higher education. Teaching and Teacher Education, $8(3), 311-317$.

Prochaska, J. O., DiClemente, C. C., \& Norcross, J. C. (1992). In search of how people change. American Psychologist, 47, 1102-1114.

Shulman, L. S. (1993). Teaching as community property. Change, 25, 6-7. 


\section{Contact:}

Fred Hebert

University of Wisconsin-Stevens Point

123 Health Enhancement Center

Stevens Point, WI 54481

(715) 346-4413 or (715) 346-2720

Email: fhebert@uwsp.edu

Marty Loy

University of Wisconsin-Stevens Point

242A College of Professional Studies

Stevens Point, WI 54481

(715) 246-2686 or (715) 346-2720

Email: mloy@uwsp.edu

Fred Hebert is Chair of the School of Health, Exercise Science, and Athletics at the University of Wisconsin-Stevens Point. He teaches courses in health education and teacher preparation and has conducted research on teaching excellence in higher education.

Marty Loy is Program Coordinator of Health Promotion in the School of Health Promotion and Human Development at the University of WisconsinStevens Point. He coordinates the College of Professional Studies faculty development efforts and heads the college Teaching Partners program. 